OPEN ACCESS

Edited by:

Suhelen Egan,

The University of New South Wales,

Australia

Reviewed by:

Martin Grube,

University of Graz, Austria

Olivier Raspé,

Botanic Garden Meise, Belgium

*Correspondence:

Carlos José Pardo-De la Hoz cj.pardo10@uniandes.edu.co

Specialty section: This article was submitted to

Microbial Symbioses,

a section of the journal

Frontiers in Microbiology

Received: 18 May 2018 Accepted: 29 October 2018 Published: 16 November 2018

Citation: Pardo-De la Hoz CJ, Magain N, Lutzoni F, Goward T, Restrepo S and Miadlikowska J (2018) Contrasting Symbiotic Patterns in Two Closely Related Lineages of Trimembered Lichens of the Genus Peltigera.

Front. Microbiol. 9:2770

doi: 10.3389/fmicb.2018.02770

\title{
Contrasting Symbiotic Patterns in Two Closely Related Lineages of Trimembered Lichens of the Genus Peltigera
}

Carlos José Pardo-De la Hoz ${ }^{1,2 *}$, Nicolas Magain ${ }^{2}$, François Lutzoni², Trevor Goward",

\footnotetext{
${ }^{1}$ Departamento de Ciencias Biológicas, Universidad de Los Andes, Bogotá, Colombia, ${ }^{2}$ Department of Biology, Duke University, Durham, NC, United States, ${ }^{3}$ UBC Herbarium, Beaty Biodiversity Museum, University of British Columbia, Vancouver, BC, Canada
}

Species circumscription is key to the characterization of patterns of specificity in symbiotic systems at a macroevolutionary scale. Here, a worldwide phylogenetic framework was used to assess the biodiversity and symbiotic patterns of association among partners in trimembered lichens from the genus Peltigera, section Chloropeltigera. We sequenced six loci of the main fungal partner and performed species discovery and validation analyses to establish putative species boundaries. Single locus phylogenies were used to establish the identity of both photobionts, Nostoc (cyanobacterium) and Coccomyxa (green alga). Distribution and specificity patterns were compared to the closely related clade, section Peltidea, which includes mainly Peltigera species with trimembered thalli. For section Chloropeltigera, eight fungal species (including five newly delimited putative species) were found in association with nine Nostoc phylogroups and two Coccomyxa species. In contrast, eight fungal species (including three newly delimited putative species) in section Peltidea were found in association with only four Nostoc phylogroups and the same two Coccomyxa species as for section Chloropeltigera. This difference in cyanobiont biodiversity between these two sections can potentially be explained by a significantly higher frequency of sexual reproductive structures in species from section Chloropeltigera compared to section Peltidea. Therefore, horizontal transmission of the cyanobiont might be more prevalent in Chloropeltigera species, while vertical transmission might be more common in Peltidea species. All Peltigera species in section Chloropeltigera are generalists in their association with Nostoc compared to more specialized Peltigera species in section Peltidea. Constrained distributions of Peltigera species that associate strictly with one species of green algae (Coccomyxa subellipsoidea) indicate that the availability of the green alga and the specificity of the interaction might be important factors limiting geographic ranges of trimembered Peltigera, in addition to constraints imposed by their interaction with Nostoc partners and by climatic factors.

Keywords: Coccomyxa, Nostoc, sexual vs. asexual reproduction, species delimitation, symbiosis 


\section{INTRODUCTION}

Delimitation of fungal species is paramount to our understanding of the level of specificity among symbiotic partners in lichens and the processes shaping their evolutionary history (e.g., Magain and Sérusiaux, 2014; Magain et al., 2016). Improvements in analytical methods have changed the way systematists delimit species (e.g., Yang and Rannala, 2010; Lumbsch and Leavitt, 2011; Reid and Carstens, 2012; Zhang et al., 2013), and unveiled the existence of an increasing number of unrecognized and mostly cryptic fungal species (e.g., Weir et al., 2012; Sato et al., 2017). The general trend has been the recognition of a large number of lichen-forming species (ca. 20,000) found in association with a few photobionts, ca. 150 (Feuerer and Hawksworth, 2007; Honegger, 2009; Perez-Ortega et al., 2012; Feuerer, 2016). Recently, studies addressing the biodiversity of photobionts in selected lichens at various spatiotemporal scales (from a single thallus to lichen communities, and from a single species to species rich genera) have become increasingly popular (e.g., Muggia et al., 2010, 2013, 2014; Thüs et al., 2011; Dal Grande et al., 2012; Perez-Ortega et al., 2012; Leavitt et al., 2013, 2015; Ruprecht et al., 2014; Yahr et al., 2015; Hestmark et al., 2016; Magain et al., 2017a,b; Moya et al., 2017). Various degrees of specificity among partners have been found in lichens. Symbiont selectivity operates in two directions (i.e., mycobiont toward photobiont and vice versa) and factors driving these symbiotic associations vary at different spatial scales and are likely to vary at different temporal scales (Fedrowitz et al., 2012; Dal Grande et al., 2014; Muggia et al., 2014; Chagnon et al., 2018; Lu et al., 2018).

The lichen-forming genus Peltigera Wild (Peltigerales, Lecanoromycetes, Ascomycota) includes bimembered and trimembered species. The former are associations between mycobionts and cyanobacteria (cyanobionts) from the genus Nostoc, while the latter comprise these two partners and green algae (phycobionts) from the genus Coccomyxa. In trimembered thalli the phycobiont is the main photobiont, whereas Nostoc is restricted to external cephalodia. Molecular systematic studies of Peltigera confirmed and clarified established infrageneric phylogenetic relationships (e.g., Goffinet et al., 2003; Miadlikowska et al., 2003; Miadlikowska and Lutzoni, 2004; O'Brien et al., 2005), including the recent re-circumscription of broadly defined species, and exploration of reciprocal levels of specificity between mycobionts and cyanobionts (O'Brien et al., 2013; Miadlikowska et al., 2014; Magain et al., 2016, 2017a,b; Chagnon et al., 2018; Lu et al., 2018). Despite these efforts, phylogenetic affiliations among some sections of Peltigera remain uncertain (e.g., the monophyly of trimembered sections, and the placement of section Hydrothyriae) and species richness seems to be underestimated (e.g., within sections Peltigera, Chloropeltigera and Horizontales). While several studies addressed the identity and phylogenetic relationships of lichenized Nostoc (e.g., O’Brien et al., 2005, 2013; Otálora et al., 2010; Fedrowitz et al., 2011; Rikkinen, 2013; Magain and Sérusiaux, 2014; Miadlikowska et al., 2014; Magain et al., 2016), very little is known about the biodiversity of the symbiotic green alga Coccomyxa (Darienko et al., 2015; Malavasi et al., 2016).

Three Peltigera sections, i.e., Chloropeltigera (three known species: P. leucophlebia, P. latiloba, and P. nigripunctata), Peltidea (five known species: P. aphthosa, P. britannica, P. chionophila, P. frippii, and P. malacea) and Phlebia (one known species: $P$. venosa), include all known trimembered Peltigera species and are composed almost exclusively of trimembered species (Miadlikowska and Lutzoni, 2000). According to Magain et al. (2017a) these three sections share a most recent common ancestor, but this relationship was not well supported. Most trimembered species of the genus Peltigera occur predominantly in the boreal biome with some exceptions where they can grow in lower latitudes but at high elevations (Martínez et al., 2003). Based on an ITS phylogeny, restricted to specimens collected in British Columbia, Canada, O'Brien et al. (2009) demonstrated that $P$. leucophlebia (section Chloropeltigera) includes at least three well-supported monophyletic groups, most likely representing putative cryptic species. To evaluate cyanobiont diversity associated with Peltigera thalli, strongly supported monophyletic groups (Nostoc phylogroups), serving as proxies for species, were circumscribed within a broad phylogenetic context of the genus Nostoc (O'Brien et al., 2013; Magain et al., 2017a). O'Brien et al. (2013) found five different Nostoc phylogroups (I, III, IV, V, and VI) in association with species of the three trimembered sections of Peltigera, each species showing a different degree of specificity toward Nostoc phylogroups. An unusually high level of reciprocal specificity between Nostoc and P. malacea was detected by O'Brien et al. (2013), which was confirmed by Miadlikowska et al. (2018) based on more specimens and additional loci. Based on a multilocus phylogenetic study, Miadlikowska et al. (2018) also found that several mycobiont clades within section Peltidea could potentially represent new species. However, none of them were formally described due to the lack of diagnostic phenotypic features, the need for a more extensive sampling, and the need to assess the level of gene flow among these putative species. Therefore, the limited span of the phylogenetic, geographical, and molecular sampling of past studies, as well as the lack of information about the third partner (Coccomyxa), did not allow a comprehensive understanding of the spatiotemporal interactions among symbionts shaping trimembered Peltigera species.

Trimembered lichens represent an ideal system to study complex symbiotic interactions. Few studies have addressed symbiotic patterns of association in trimembered lichens within the context of robust phylogenies inferred for each of the three partners. The ancestral symbiotic state for the genus Peltigera is bimembered (one mycobiont in association with one cyanobiont), which is also the case for the entire order Peltigerales (Miadlikowska and Lutzoni, 2004). In other genera with bimembered and trimembered thalli (such as Nephroma), some evidence suggests that the evolutionary acquisition of a green algal partner by bimembered cyanolichens was accompanied by a change in cyanobiont composition (Lohtander et al., 2003; Fedrowitz et al., 2012). Specificity patterns toward Nostoc have also been hypothesized to be different between bimembered and trimembered species, the latter being associated with a 
narrower set of Nostoc lineages (Elvebakk et al., 2008). Also, the mode of reproduction (sexual vs. asexual) of the lichenforming fungus is linked to the type of photobiont transmission from one generation to the next (horizontal vs. vertical, respectively), which can be an important factor driving symbiotic specificity. Sexually reproducing fungal species must reacquire their photobiont at each generation, favoring generalists, whereas asexually reproducing species promote vertical transmission of their photobionts, which is likely to result in high reciprocal specificity (Paulsrud et al., 1998; Otálora et al., 2010; Dal Grande et al., 2012; Hestmark et al., 2016; Magain et al., 2017a).

In this study we assembled a multilocus dataset for Peltigera species, and a single locus dataset for each of the photosynthetic partners (Nostoc and Coccomyxa), from section Chloropeltigera (and for selected representatives from section Peltidea), to generate a worldwide phylogeny for this section. We discuss the potential contribution of various biotic and abiotic factors (i.e., symbiont distribution, diversification rates, and photobiont transmission) in shaping the spatial and evolutionary patterns of symbiotic association and levels of specificity among the three main partners of these lichens.

\section{MATERIALS AND METHODS}

\section{Taxon Sampling}

Ninety-two specimens from section Chloropeltigera were chosen across its global distribution (mostly the boreal biome) for this study. These individuals were selected from herbarium material and collected by the authors and collaborators during fieldtrips in China, Russia, Norway, Iceland, Canada, and the United States. Additionally, 32 specimens from section Peltidea used in Miadlikowska et al. (2018) were also included. Supplementary Table S1 summarizes the voucher information for each specimen used.

\section{Molecular Data Acquisition}

Total DNA was extracted from fresh and herbarium specimens lacking visual symptoms of fungal infections. We followed a modified protocol from Zolan and Pukkila (1986) using 2\% sodium dodecyl sulphate (SDS) as extraction buffer. In order to get sufficient amounts of DNA for cyanobionts, several cephalodia were collected from multiple thallus lobes. For the mycobiont, we sequenced six loci, including one nuclear ribosomal locus: the Internal Transcribed Spacer (ITS) using primers ITS1F and ITS4 (White et al., 1990); two protein coding genes: $\beta$-tubulin $(\beta$-tub) using primers bt_34F (O'Brien et al., 2009) and BT2B (Glass and Donaldson, 1995), and the RNA Polymerase II largest subunit (RPB1) using primers RPB1-AF (Stiller and Hall, 1997) and RPB1-CR (Matheny et al., 2002); and the non-coding part of three Collinear Orthologous Regions (COR) that were recently selected based on genomic synteny analyses: COR $1 \mathrm{~b}$ using primers COR-1bF and COR-1bR-B, COR3 using primers COR-3F-A and COR-3R-B, and COR16 with primers COR-16Fout and COR-16Rmid1 (Magain et al., 2017b). To amplify the three COR markers we followed the PCR protocol included in Magain et al. (2017b), whereas for the remaining loci we used the conditions described in Miadlikowska et al. (2014).

The rbcLX locus of Nostoc (comprised of the last 82 amino acids of the RUBISCO large subunit, a putative chaperone gene $[r b c X]$ and two intergenic spacers) was amplified using primers CX and CW (Rudi et al., 1998) following the protocol of O'Brien et al. (2013). Cocccomyxa-specific primers were designed to target the ITS region of this algal photobiont using DNA isolated from the entire thallus (ITSCOF: 5' GAC GGA GAT TTT CAA GTT GG 3'; ITSCOR: 5' CCT CCC ACC TAG AGG AAG G 3'). The following PCR settings were used: $94^{\circ} \mathrm{C}$ for $1 \mathrm{~min}$; 35 cycles of $94^{\circ} \mathrm{C}$ for $30 \mathrm{~s}, 55^{\circ} \mathrm{C}$ for $30 \mathrm{~s}$ and $72^{\circ} \mathrm{C}$ for $1 \mathrm{~min}$; and a final elongation at $72^{\circ} \mathrm{C}$ for $10 \mathrm{~min}$.

All PCR reactions were carried out in a final volume of $25 \mu \mathrm{L}$ containing $2.5 \mu \mathrm{L}$ of buffer, $2.5 \mu \mathrm{L}$ of $10 \mathrm{mM}$ dNTPs, $1.25 \mu \mathrm{L}$ of $10 \mathrm{mM}$ primers, $0.15 \mu \mathrm{L}$ of TargeTaq ${ }^{\mathrm{TM}}$ (Southern BioLabs, Cary, NC, United States), $2.5 \mu \mathrm{L}$ of BSA, $15 \mu \mathrm{L}$ of doublesterilized ultrapure $\mathrm{H}_{2} \mathrm{O}$ and $1 \mu \mathrm{L}$ of DNA. All PCR products were cleaned and sequenced as described in Miadlikowska et al. (2014). All sequences were assembled using Geneious v. 7.1. (Drummond et al., 2011). GenBank accession numbers are listed in Supplementary Table S1.

\section{Multiple Sequence Alignments and Datasets}

All sequences were subjected to BLAST searches using GenBank database to confirm their expected identity. Multiple sequence alignments were generated for each locus using the MAFFT v. 7 (Katoh and Standley, 2013) online platform ${ }^{1}$ with the Q-INS-i strategy. Alignments were then adjusted manually using MacClade v. 4.08 (Maddison and Maddison, 2005) and Mesquite v. 2.75 (Maddison and Maddison, 2010). Manually delimited ambiguously aligned regions (following Lutzoni et al., 2000) were excluded from subsequent phylogenetic analyses. Single locus maximum likelihood phylogenetic analyses were performed for the mycobiont to detect topological conflicts with a $70 \%$ bootstrap threshold using the Hypha package (Oliver et al., 2013) as implemented in Mesquite v. 2.75.

As no significant conflicts were found between single-locus phylogenies, four datasets were assembled: (1) a mycobiont concatenated matrix with 42 ingroup taxa comprising all specimens from section Chloropeltigera with at least four of the six targeted loci, and eight outgroup taxa from sections Phlebia and Peltidea; (2) a Nostoc matrix with a total of 425 rbcLX sequences representing a broad sampling of published symbiotic and free-living Nostoc from Nostoc Clade I, and Clade II subclades 1, 2, and 3 (sensu Magain et al., 2017a), including 54 new sequences generated for this study and 28 from Miadlikowska et al. (2018); (3) a Coccomyxa matrix consisting of 81 new ITS sequences generated as part of this study and 70 sequences from the latest systematic revision of this genus (Malavasi et al., 2016), including both freeliving and lichenized Coccomyxa found in association with Ascomycota (ascolichens) and Basidiomycota (basidiolichens); and (4) a concatenated matrix for single representatives

${ }^{1}$ http://mafft.cbrc.jp/alignment/server/ 
of each of the 17 species from sections Chloropeltigera, Peltidea and Phlebia for which sequences from the same four loci were available (ITS, $\beta$-tubulin, COR1b and COR3). Perl scripts “compare_and_choose.pl," "adapt_from_file.pl," and "exclude_and_adapt.pl" (Magain, unpublished) were used to prepare the concatenated matrices used in this study. All alignments and phylogenies were deposited in TreeBASE ${ }^{2}$ (Pardo-De la Hoz et al., 2018).

\section{Phylogenetic Analyses}

PartitionFinder V.1.1.1 (Lanfear et al., 2012) was used to find the best partition scheme and model of nucleotide substitution for both single and multilocus datasets using the rcluster search algorithm and the corrected Akaike Information Criterion (AICc). The search was performed with the following starting subsets: (1) ITS1, 5.8S, ITS2, $\beta$-tubulin 1st, 2nd, 3rd codon positions and introns, $R P B 1$ 1st, 2nd, 3rd codon positions and intron, COR1b, COR3 and COR16 for the concatenated mycobiont matrix; (2) rbcL 1st, 2nd, 3rd codon positions and $r b c X$ 1st, 2nd, 3rd codon positions for the Nostoc matrix; (3) ITS1, 5.8S and ITS2 for the Coccomyxa matrix; and (4) ITS1, 5.8S, ITS2, $\beta$-tubulin 1st, 2nd, 3rd codon positions and introns, COR1b and COR3 for the matrix covering three sections of the genus Peltigera. Maximum likelihood (ML) searches for the most likely tree and bootstrap replicates (1000) were performed on each dataset using RAxML HPC2 v. 8 (Stamatakis et al., 2008; Stamatakis, 2014) as implemented in CIPRES (Miller et al., 2010) using the GTRGAMMA model estimated for each data subset.

\section{Mycobiont Species Delimitation}

We coupled species discovery and validation methods to delimitate mycobiont species (Leavitt et al., 2015; Magain et al., 2017b). For section Chloropeltigera, we used the ML tree estimated based on the concatenated mycobiont matrix to infer putative species boundaries with the Maximum Likelihood Poisson Tree Process (PTP; Zhang et al., 2013) as implemented on the web server ${ }^{3}$. We generated single locus chronograms using an uncorrelated lognormal relaxed clock in BEAST $\mathrm{v}$ 1.8.3 (Drummond and Rambaut, 2007; Drummond et al., 2013) with default priors. We performed two independent BEAST searches with four chains each. Both searches were run for $10,000,000$ generations sampling every 1000th generation for a total sample size of 20,000 trees. Effective sample size for the estimated parameters and convergence was assessed in Tracer v 1.6 (Rambaut and Drummond, 2013). For each locus, a set of 500 trees from the estimated posterior distribution were subsampled using LogCombiner v. 1.8.2 (Rambaut and Drummond, 2015) after discarding $10 \%$ of the samples as burnin. These sets of trees were used to infer single locusbased species delimitations using a bayesian implementation of the Generalized Mixed Yule Coalescent model (bGMYC) (Reid and Carstens, 2012). The bGMYC analyses were run for 50,000 generations with threshold values of 2 and 25 and a starting point of " $1,1,25$." The thinning parameter was set to

${ }^{2}$ http://purl.org/phylo/treebase/phylows/study/TB2:S23188

${ }^{3}$ http://species.h-its.org/
100 and the burnin to 10,000 samples. We assigned individuals to putative species when the probability of grouping haplotypes together was higher than the probability of all alternative groupings that included at least one haplotype from this putative species.

The most splitting delimitation scheme inferred with the discovery methods was set as prior for species validation in Bayesian Phylogenetics and Phylogeography (BP\&P) (Rannala and Yang, 2003; Yang and Rannala, 2010) using the concatenated mycobiont matrix. The gamma distribution parameter priors for $\tau$ and $\theta$ were set to $G(2,1000)$ and $G(2,100)$. The analysis was run for 1,000,000 generations sampling every 10th generation and discarding the first $10 \%$ as burnin. Daughter lineages of nodes with posterior probabilities of speciation $\geq 0.95$ were considered well-supported species. An additional bGMYC analysis was run on a matrix combining our mycobiont ITS dataset with the ITS sequences from section Peltidea generated by Miadlikowska et al. (2018). The purpose of this analysis was to generate a species delimitation scheme within a phylogenetic framework that included all Peltigera sections with trimembered taxa. This uniform approach to species delimitation across these three sections enabled inter-section comparisons of specificity and mode of reproduction (sexual vs. asexual) for all known trimembered Peltigera lichens.

\section{Symbiont Specificity Assessment}

To account for the differences in cyanobiont sample sizes between mycobiont species, a rarefaction analysis was performed to estimate the distribution of the number of Nostoc phylogroups as a function of the number of samples per section (Peltidea and Chloropeltigera). The R package iNEXT v. 1.0 (Hsieh et al., 2013) was used for the rarefaction analysis with 50 bootstrap replicates to generate a $95 \%$ confidence interval.

\section{Quantification of Sexual and Asexual Reproduction}

We examined 253 well-preserved specimens (116 sequenced in this study and listed in Supplementary Table S1; 137 from Miadlikowska et al., 2018) and scored them for the presence or absence of apothecia as a proxy for sexual vs. asexual reproduction. ITS haplotype diversity $(H)$ was computed for each species using equation 1 .

$$
H=\frac{N}{N-1}\left(1-\sum_{\mathrm{i}} x_{\mathrm{i}}^{2}\right)(\text { Nei and Tajima, 1981) }
$$

where $x_{\mathrm{i}}$ is the relative frequency of each haplotype in the sample and $N$ is the total sample size (i.e., the number of haplotypes from each species). A linear regression and a statistical correlation test were done in $\mathrm{R}$ considering all species with more than 10 available samples. We used the R package iNEXT for the estimation of the rarefaction curves and for comparing the distribution of the number of ITS haplotypes as a function of the sample size per section between Chloropeltigera and Peltidea. Fifty bootstrap replicates were completed to generate a $95 \%$ confidence interval. 


\section{RESULTS}

\section{Mycobiont Phylogeny and Species Delimitation}

Based on the BP\&P species validation method, section Chloropeltigera comprised eight well-supported lineages (i.e., speciation posterior probability $\geq 0.95$ ), which might represent species (Figure 1). P. leucophlebia sensu lato was recovered as non-monophyletic because it comprised P. latiloba (Figure 1 and Supplementary Figure S1). Most analyses split P. leucophlebia s. l. (Figure 1) into five to six distinct lineages. However, a few conflicts were observed between the species delimitation schemes inferred with the discovery methods and their validation with BP\&P (e.g., the split between P. leucophlebia 3 and P. leucophlebia
Mycobiont, RAXML best tree

ITS + $\beta$-tub. + RPB1 + COR1b + COR3 + COR16 3843 characters, 50 specimens
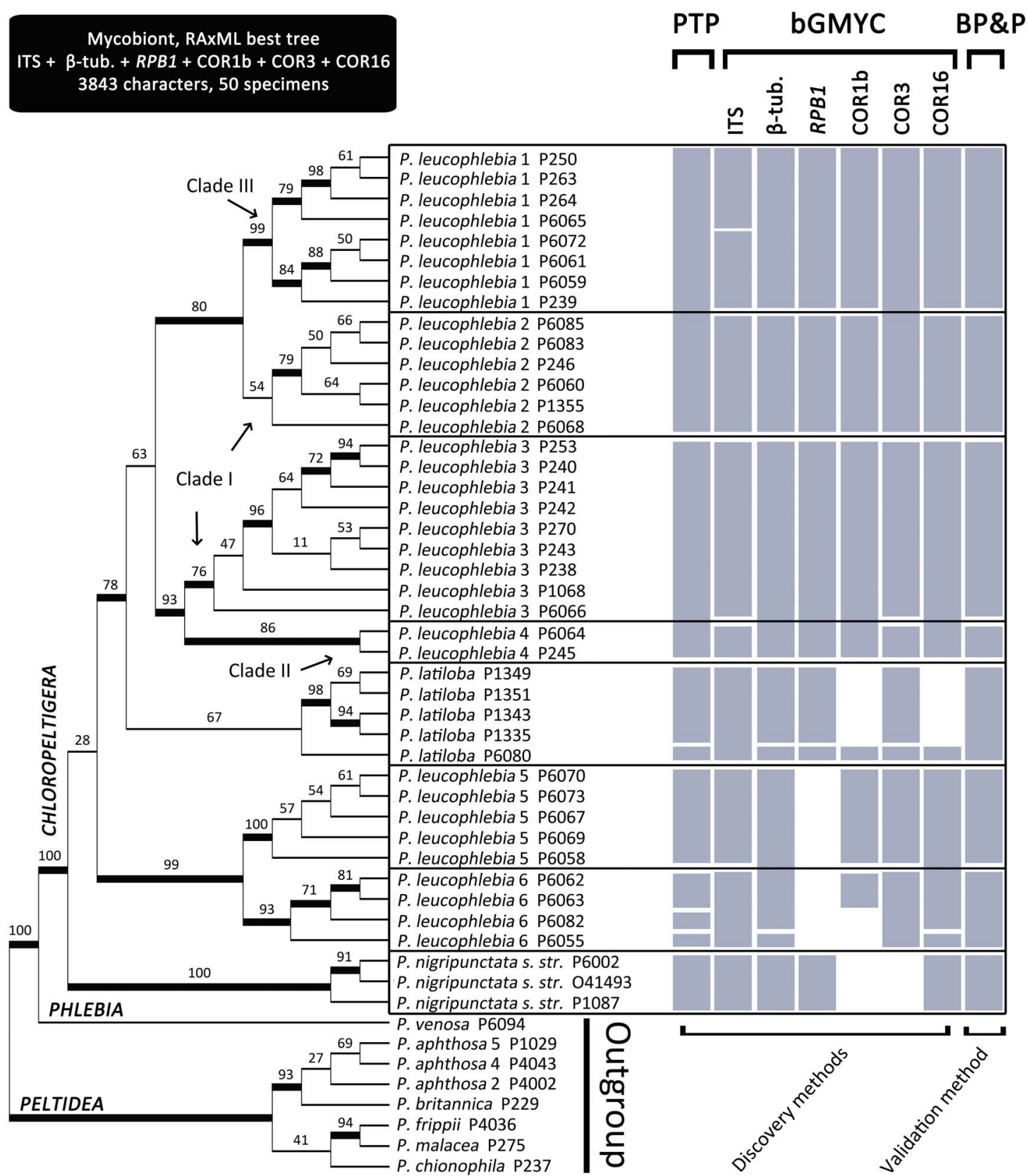

FIGURE 1 | Maximum likelihood phylogeny of Peltigera section Chloropeltigera (mycobiont) based on six combined loci. Species were delimited by implementing discovery (PTP and bGMYC) and validation (BP\&P) methods on 42 specimens from section Chloropeltigera. Representatives of sections Phlebia and Peltidea were used as outgroup (Magain et al., 2017a). Numbers above branches are bootstrap proportions and thick branches represent nodes with bootstrap values $\geq 70 \%$. Gray bars represent species delimitation scheme inferred by each method. Boxes indicate species delimitation based on BP\&P. Arrows indicate the three putative cryptic clades within P. leucophlebia s. lat. reported in O'Brien et al. (2009). 
4). Newly delimited lineages within P. leucophlebia s. l. were well supported (bootstrap values above 75\%), except for the monophyly of $P$. leucophlebia 2, which received a bootstrap support of $54 \%$ (Figure 1 and Supplementary Figure S1). The monophyly of $P$. latiloba was recovered with bootstrap support of $67 \%$ and was nested inside P. leucophlebia s. $l$. (Figure $\mathbf{1}$ and Supplementary Figure S1). Four of the discovery analyses split this species into two distinct lineages, i.e., specimen P6080 represents one lineage distinguishable from the remaining individuals that form a wellsupported clade. However, BP\&P merged these two lineages into one ( $\mathrm{pp}=0.96$; Figure 1). The bGMYC analysis performed on the ITS matrix for sections Chloropeltigera and Peltidea (combined) delimited the same species as the BP\&P analysis restricted to section Chloropeltigera (result not shown).

\section{Photobiont Identity}

Eighty Nostoc rbcLX sequences, obtained from the three sections of the genus Peltigera with trimembered lichens, clustered in 12 monophyletic groups (Nostoc phylogroups) in the ML tree (Figure 2), following phylogroups designation sensu Magain et al. (2017a). Seven of these phylogroups had strong bootstrap support ( $\geq 70 \%$; Figure 2). Two of these phylogroups (III and IV) are part of Nostoc clade 2 subclade 2 sensu Otálora et al. (2010), while the remaining phylogroups belong to Nostoc clade 2 subclade 3 (Figure 2). Three sequences that could not be assigned to any known phylogroup (i.e., phylogenetically placed outside existing and newly defined phylogroups) were labeled using an $r b c L X$ unique haplotype number (Supplementary Table S1).

The ITS phylogeny for Coccomyxa (Figure 3) revealed the same major clades and all species-level phylogenetic relationships reported by Malavasi et al. (2016). Newly added sequences from trimembered Peltigera species fell inside two strongly supported species: C. solorinae and C. subellipsoidea. The latter clade comprises photobionts associated with lichen-forming fungi from both Ascomycota and Basidiomycota phyla, whereas C. solorinae has been found only in association with Ascomycota fungi (Figure 3).

\section{Symbiotic Specificity and Geographic Patterns}

Peltigera species from section Chloropeltigera were found in association with nine Nostoc phylogroups, each species associating with up to seven phylogroups (no data were available for P. nigripunctata s. str.) (Figure 4). Species in section Peltidea were found in association with four phylogroups, each species associating with no more than two phylogroups. The cyanobiont from the only individual of $P$. venosa (section Phlebia) studied by us was identified as a rare Nostoc phylogroup (XLIV). Phylogroups (III and IV) from Nostoc clade 2 subclade 2 (Figure 2) are associated exclusively with Peltigera species from section Peltidea, whereas phylogroups from Nostoc clade 2 subclade 3 were found in association with species from all three sections (Chloropeltigera, Phlebia and Peltidea).

Both Coccomyxa solorinae and C. subellipsoidea were present in all three Peltigera sections without any obvious patterns of specificity toward a single fungus or cyanobiont (Figure 4).
However, some mycobiont species showed preference for one of the two Coccomyxa species, e.g., P. leucophlebia 3 was always found with C. subellipsoidea, whereas P. leucophlebia 6 was found with C. solorinae.

In general, Peltigera species within these three sections, and their Nostoc phylogroups, have wide geographic distributions, except $P$. chionophila and $P$. nigripunctata s. str. 1 which are restricted to the Pacific North West (PNW) and South East Asia (SEA), respectively (Figure 4 and Supplementary Table S1). Coccomyxa solorinae was present in every sampled region whereas C. subellipsoidea was only found in North America (Supplementary Table S1).

\section{Proportion of Sexual vs. Asexual Reproduction}

A significant positive correlation $(p<0.05)$ was found between the proportion of specimens with apothecia and ITS haplotype diversity $(H)$ in species from sections Chloropeltigera and Peltidea (Figure 5B). There were twice as many ITS haplotypes in section Chloropeltigera as in section Peltidea when accounting for sample sizes (Figure 5C). The proportion of specimens with apothecia in section Chloropeltigera (0.39) was nearly twice as large as for section Peltidea (0.21; Figure 5D). In general, species from section Chloropeltigera showed higher ITS haplotype diversity and higher proportion of specimens with sexual structures (apothecia) than most species from section Peltidea (Figure 5B).

\section{DISCUSSION}

\section{Mycobiont Species Delimitation}

Previous studies have already shown the putative cryptic biodiversity within section Chloropeltigera (O'Brien et al., 2009). Based on ITS sequences from specimens collected in British Columbia, three well-supported clades were identified within P. leucophlebia s. l., however, no morphological characters to recognize them as separate species were provided. Using a broader molecular and geographical sampling, we confirm two (Clade II and Clade III) of these lineages within this section (Figure 1). Together with the three currently recognized species (P. leucophlebia, P. latiloba and P. nigripunctata) (HoltanHartwig, 1993, 2005; Vitikainen, 1994), section Chloropeltigera contains at least eight putative species, five of which are new and represent $P$. leucophlebia s. $l$. A more extensive sampling might reveal that $P$. latiloba represents two species (P6080 was recognized by PTP and bGMYC as a different putative species). These results can serve as a starting point for a study designed to assess gene flow. The apparent lack of distinguishing phenotypic traits among these putative species could result from gene flow and may be reflected in species population dynamics.

\section{Photobiont Identity, Distributions, and Switches}

We found 12 Nostoc phylogroups (sensu Magain et al., 2017a) consorting with Peltigera in the three sections Chloropeltigera, Pelidea, and Phlebia (Figure 2). Phylogroups III, IV, V, and 

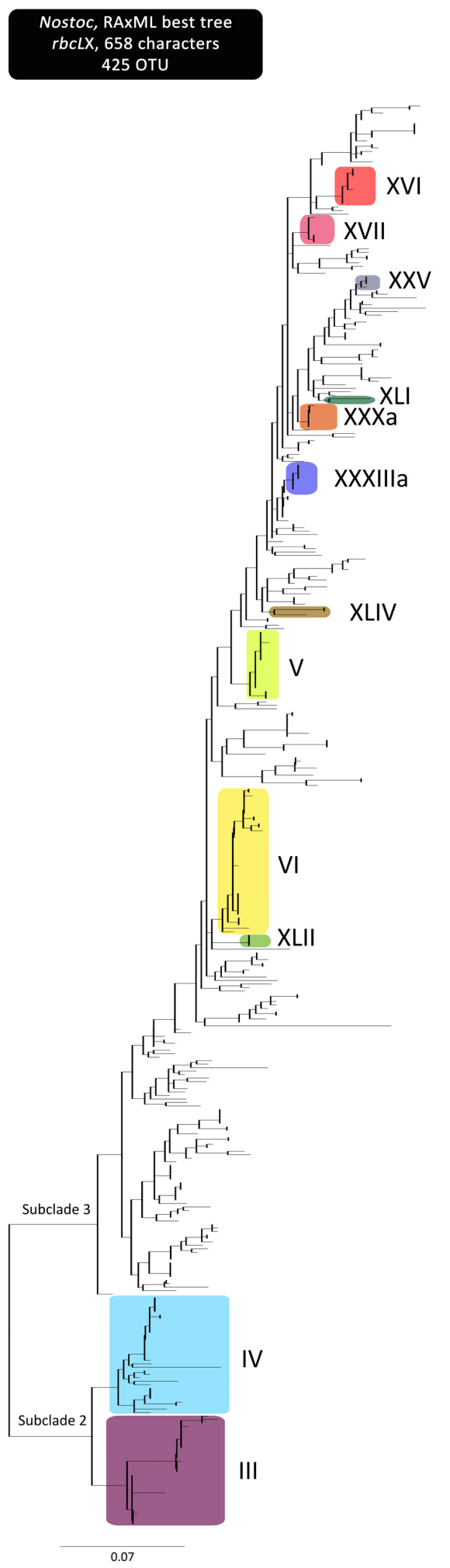

$x x V$

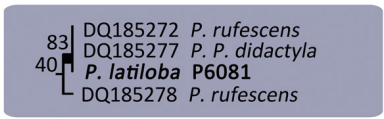

XXXIIIa

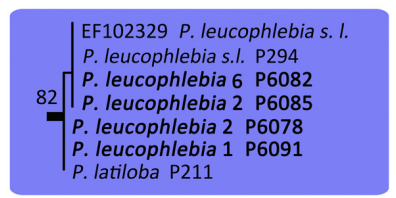

XLIV

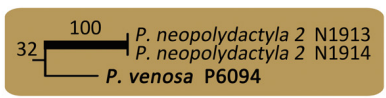

VI

P. latiloba P6080

- KC437665 P. aphthosa s. I.

KC437826 P. leucophlebia s. I.

KC437789 P. leucophlebia s. I.

KC437676 P. leucophlebia s. I.

KC437876 P. neopolydactyla
P. leucophlebia 5 P290

$H_{P \text {. aphthosa } 1 \text { P1 P1340 }}^{\text {P. aphthosa s. I. P1341 }}$

$-C_{P \text {. leucophlebia } 1 \text { P6050 }}^{\text {DQ185275 P. rufescens }}$

P. leucophlebia 6 P6052

P. leucophlebia 1 P6076

P. leucophlebia 3 P240

P. leucophlebia 1 P239

P. leucophlebia 4 P6077

P. leucophlebia 2 P1118

P. leucophlebia 2 P286

P. leucophlebia 4 P6074

P. leucophlebia 2 P6083

P. leucophlebia 3 P6066

P. leucophlebia 6 P6062

P. britannica 1 P200

P. leucophlebia 2 P287

P. aphthosa 5 P1114

P. leucophlebia 3 P270

P. leucophlebia 3 P238

. leucophlebia 4 P267

KC437711 P. praetextata

P. leucophlebia s. I. P241

DQ185312 P. aphthosas.

P. leucophlebia s. I. P249

P. leucophlebia 1 P264

41 P. leucophlebia 3 P253

P. leucophlebia s. I. P17

P. aphthosa 1 P1332

P. aphthosa 4 P1336

IV

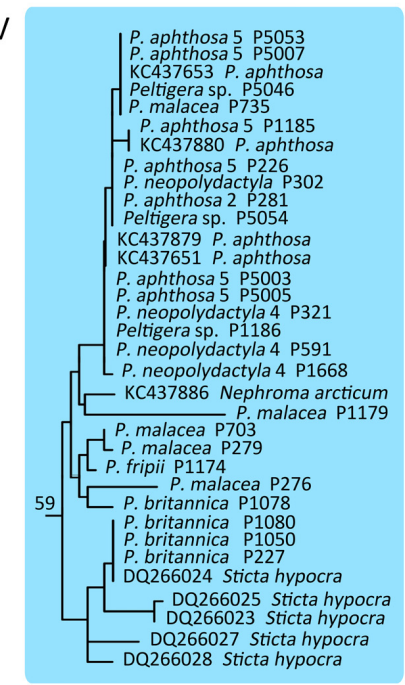

XXXa

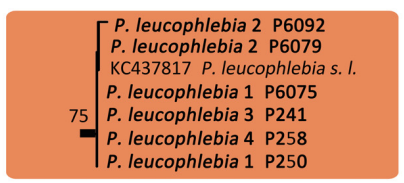

XVI

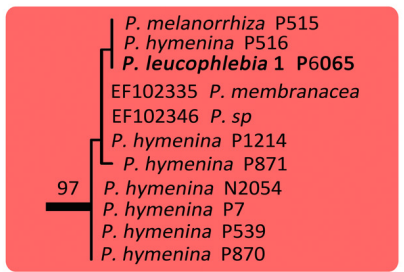

V

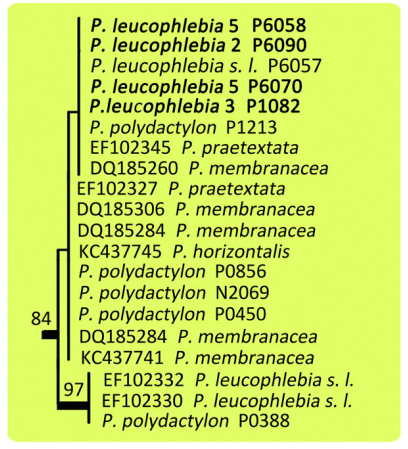

XVIII

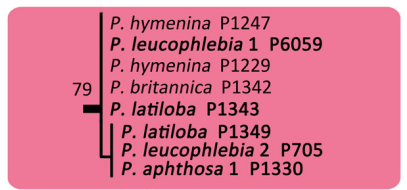

XLI

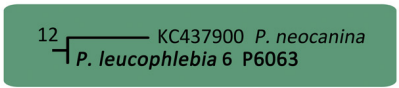

XLII

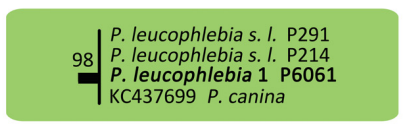

III

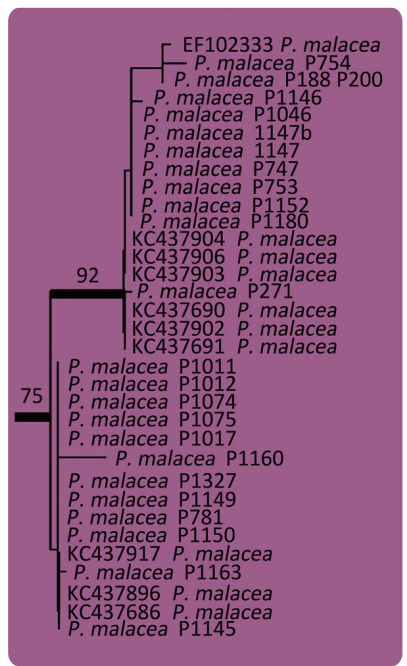

FIGURE 2 | Nostoc rbcLX maximum likelihood phylogeny. Clades highlighted with colors on the complete tree, without tip labels, on the left, correspond to the phylogroups associated with Peltigera species included in this study. Detailed tip labels are shown on the clades on the right. Top left Roman numerals correspond to the Nostoc phylogroup numbering system initiated by O'Brien et al. (2013) and further developed by Magain et al. (2017a). Tip label names correspond to the mycobiont forming the thallus within which the Nostoc strain was sequenced. Names in bold correspond to the sequences generated in this study. Thick branches represent bootstrap support $\geq 70 \%$. 


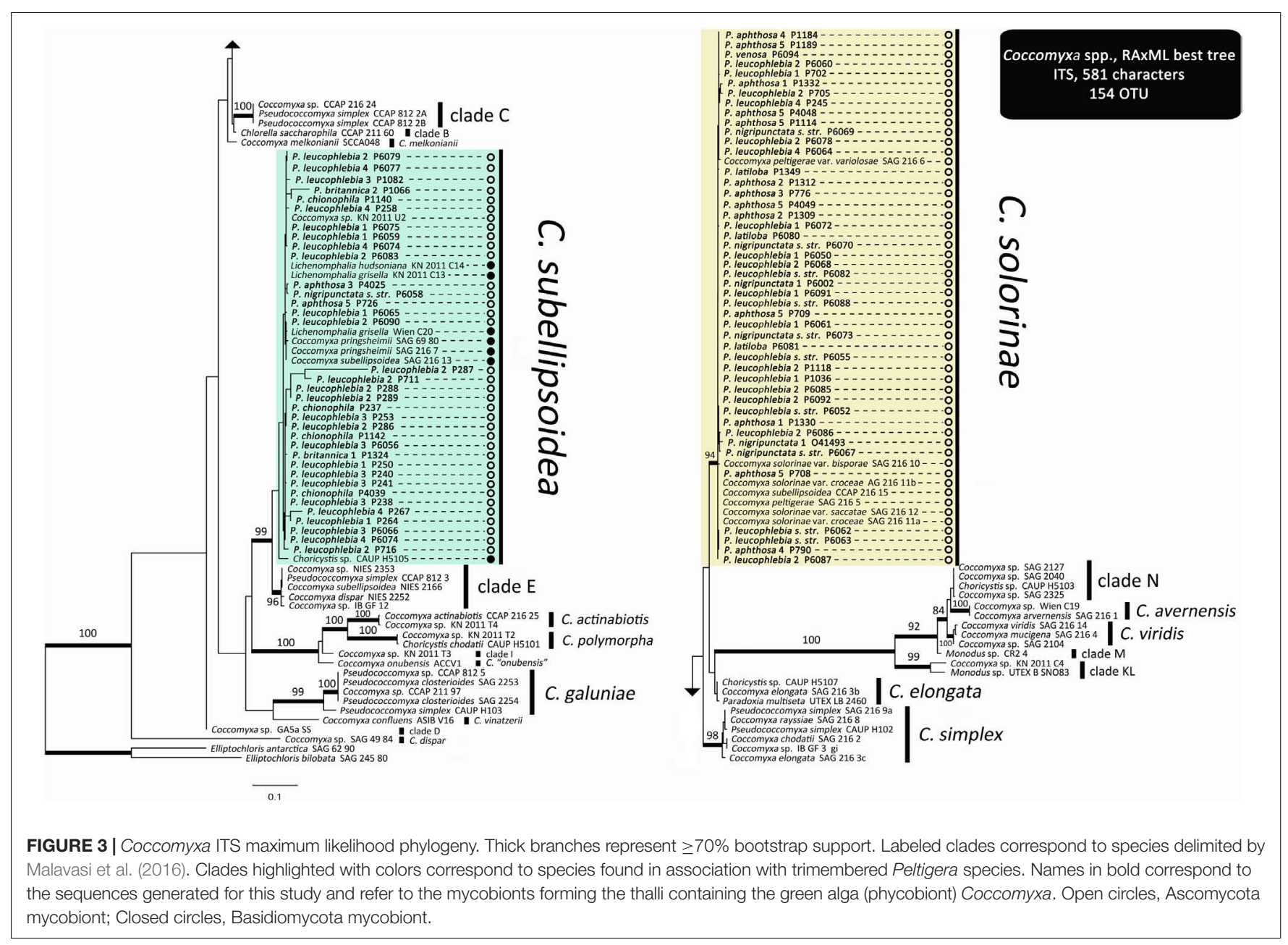

VI had already been reported to consort with trimembered Peltigera species (O’Brien et al., 2013). In that study, one specimen of $P$. britannica (section Peltidea) consorted with Nostoc phylogroup I, a finding not confirmed by us perhaps due to low sampling. The remaining associations between the mycobiont species and Nostoc phylogroups reported by O'Brien et al. (2013) from sections Chloropeltigera and Peltidea were confirmed and expanded by our study. Phylogenetic branching and very short internodes recovered for most of the phylogroups suggest a predominantly clonal population structure (Figure 2), as reported previously for Peltigera-associated Nostoc, including from trimembered sections by O'Brien et al. (2013), and from several cyanolichen genera (Wirtz et al., 2003). This pattern is consistent with the hypothesis that recombination among the symbiotic Nostoc is not frequent in nature, however, in contrast with other studies which reported phylogenetic incongruence among different loci sequenced for these cyanobionts (O'Brien et al., 2005; Kaasalainen et al., 2012).

The primers designed for this study allowed cultureindependent amplification of the ITS locus for Coccomyxa using metagenomic DNA extracted from lichen thalli. Our phylogeny for Coccomyxa is consistent with the hypothesis that lichenization occurred twice during the evolutionary history of this genus (Figure 3). So far, C. solorinae has been found only in two sister lichen genera, Peltigera and Solorina (Peltigeraceae, Ascomycota), while C. subellipsoidea, previously reported only from the basidiolichen genus Lichenomphalia (Zoller and Lutzoni, 2003; Muggia et al., 2011; Yahr et al., 2015), is now known to consort also with Peltigera (Figure 3). We conclude that there is no reciprocal specificity between these algal species and members of these two fungal phyla. Moreover, we found substantially less biodiversity in Coccomyxa (two species: C. solorinae and C. subellipsoidea) than in Nostoc (12 phylogroups) associated with 17 putative Peltigera species in these three sections (Figure 4).

Most of the putative Peltigera species included in this study have wide distributions across the boreal biome. In contrast, P. chionophila and P. leucophlebia 3 seem to be restricted to North America and specifically associate with C. subellipsoidea (Figure 4), which was only found in North America (Figure 4 and Supplementary Table S1). Because C. subellipsoidea can also associate with other Peltigera species with wider geographic distributions, $P$. chionophila and $P$. leucophlebia 3 may represent cases where the distribution of the photobiont limits the geographic range of the mycobiont (Louthan et al., 2015). 


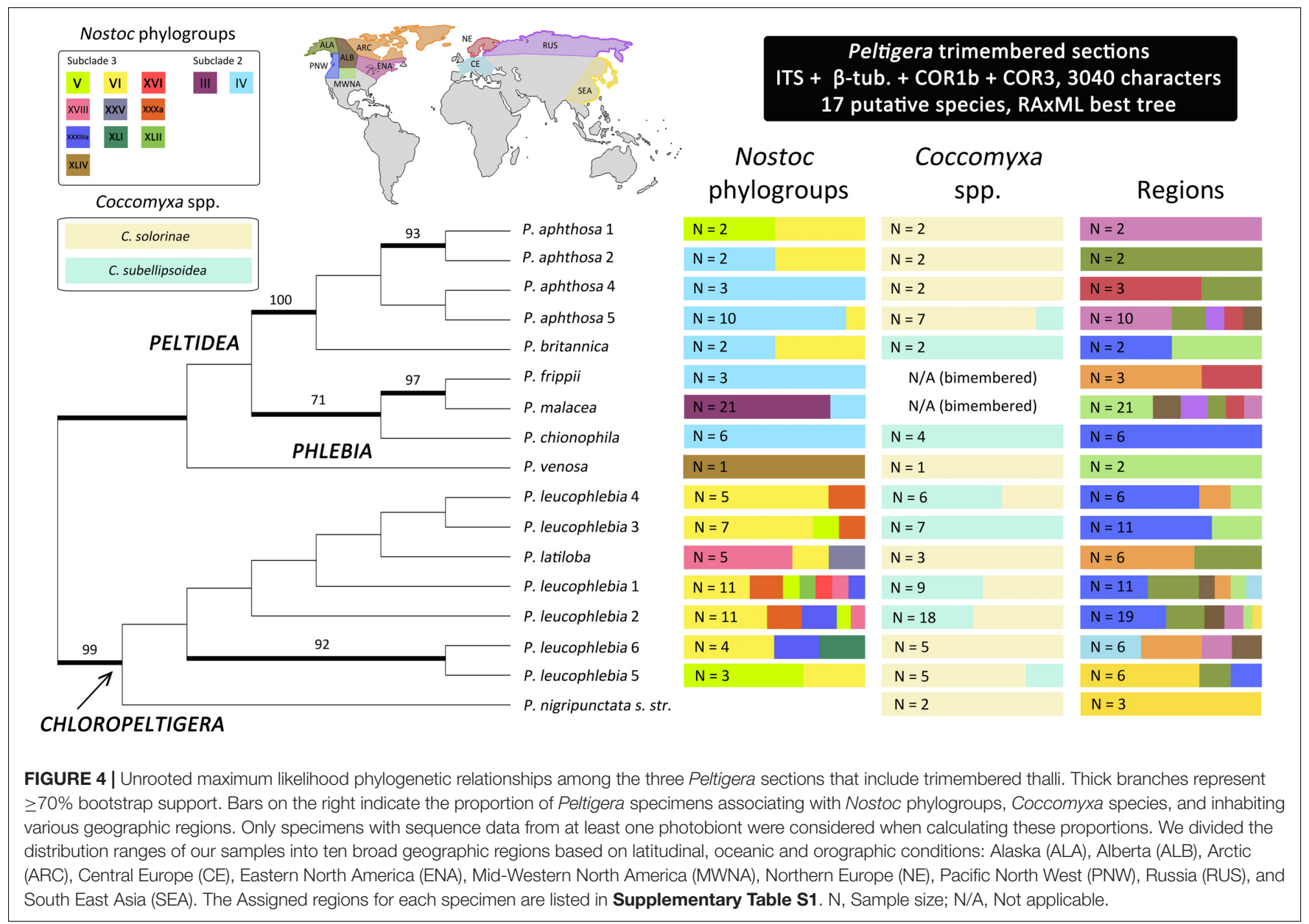

P. chionophila is restricted to regions with a heavy, prolonged snow cover (Goward and Goffinet, 2000). The signatures of adaptation to cold environments found in the C. subellipsoidea genome by Blanc et al. (2012) could indicate that this alga plays a role in the snow tolerance observed in $P$. chionophila. However, because C. subellipsoidea is found in association with several other lichenized fungi, which grow in broader environmental conditions (e.g., P. leucophlebia 3, Lichenomphalia spp.), it is likely that additional factors are related to the snow tolerance displayed by $P$. chionophila. It was previously demonstrated that photobiont switches and associations with a higher number of photobionts (generalist pattern of association for a mycobiont species) can be associated with the colonization of new niches and geographic regions by the mycobionts, followed by a subsequent increase in specificity (specialist pattern of association) (Fernández-Mendoza et al., 2011; Magain et al., 2017a). However, some aspects of these patterns of association are spatially scale-dependent (Chagnon et al., 2018; Lu et al., 2018). Within the boreal biome, climatic factors are more limiting for some mycobionts than the availability of their photobiont, as was recently demonstrated for a few Peltigera species from section Polydactylon across the boreal zone in Québec, Canada (Lu et al., 2018). Therefore, these photobiont switches are perhaps more likely at an interbiome scale, or its equivalent along an altitudinal gradient, and involves mycobiont species with distributions covering more than one biome. Previously reported shifts in lichen-associated algal communities (Trebouxia photobionts of Lecanora rupicula and Lasallia) along altitudinal gradients (Blaha et al., 2006; Dal Grande et al., 2018) support the hypothesis that the abiotic environment may act as filter for both partners of the symbiosis, hence shaping their partnership as well as geographic ranges. Constrained distributions can also result from increased symbiotic specificity (Magain et al., 2017a). This can be the product of ancient coevolutionary histories (Thompson, 2005; Magain et al., 2017a) coupled with interspecies signaling needed to reconstitute the lichen symbiosis when the photobiont is transmitted horizontally (Etges and Ott, 2001).

Most Peltigera species form bimembered thalli with Nostoc as their only photobiont, and they can be found in all biomes (Martínez et al., 2003). However, the mainly boreal distributions of trimembered Peltigera species (so far not reported from the Southern Hemisphere) seem limited by the ranges of the green alga Coccomyxa, which appears to be adapted to cold environments (Blanc et al., 2012). In contrast, lichenized Nostoc associated with Peltigera are widespread across vast geographic regions and, therefore, are less likely to limit the distribution of Peltigera species (Lu et al., 2018). Several 
A

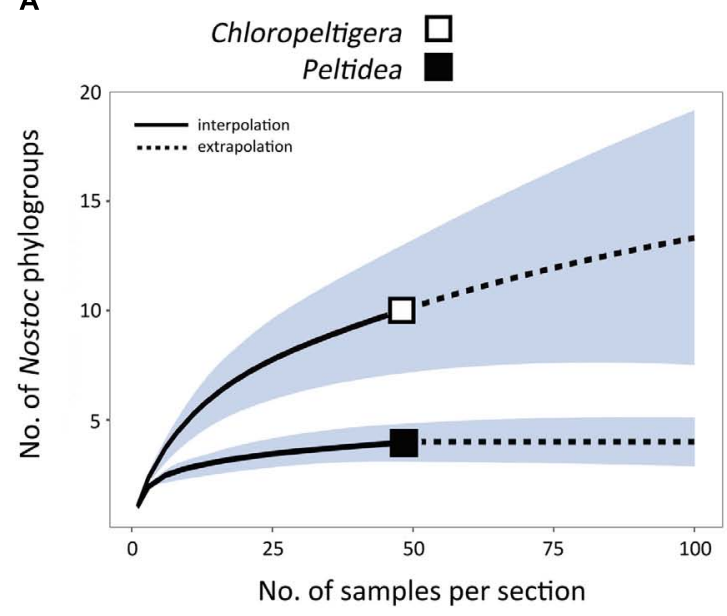

C

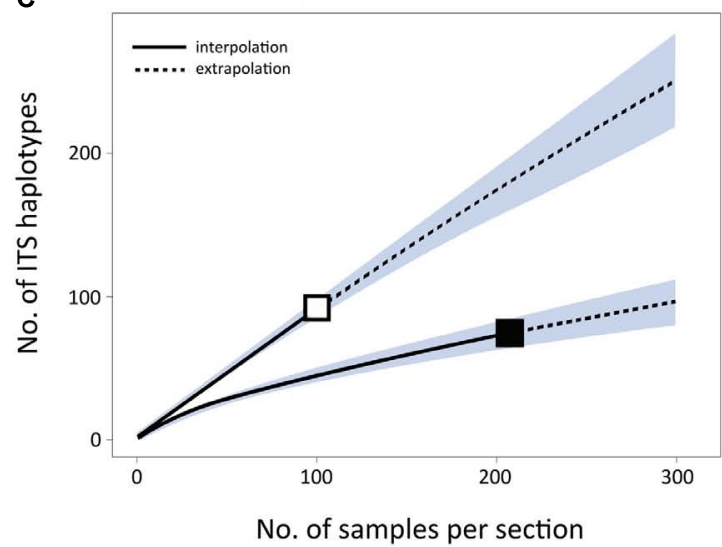

B

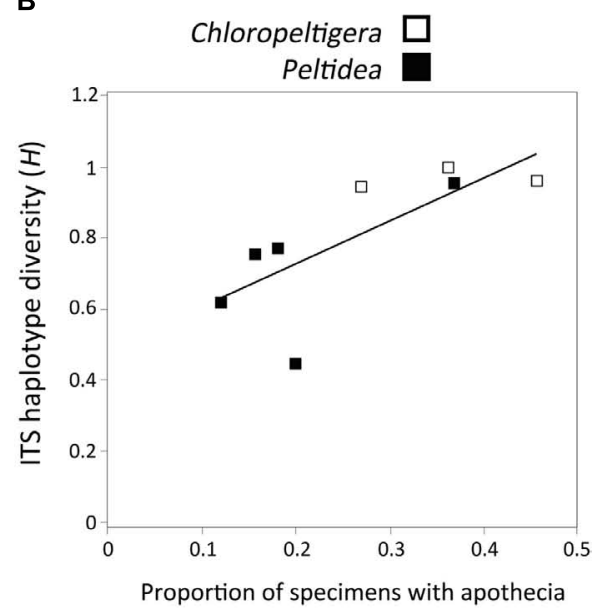

D

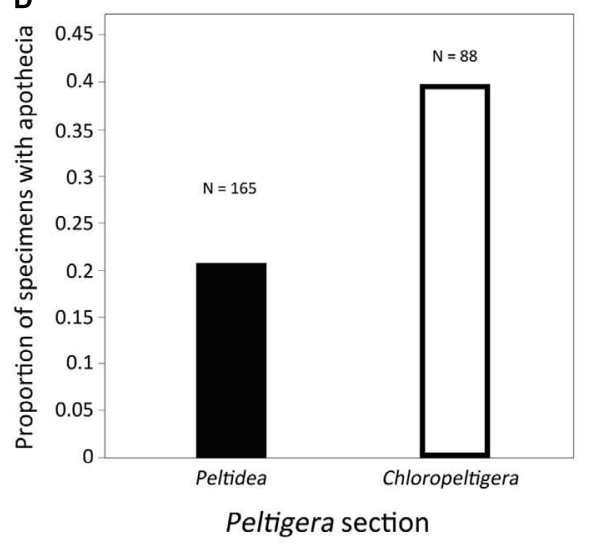

FIGURE 5 | Assessment of specificity and reproductive mode in sections Chloropeltigera and Peltidea. (A) Rarefaction curve showing the distribution of the number of Nostoc phylogroups as a function of the number of samples per section. Shaded areas represent the $95 \%$ confidence intervals. (B) Correlation between ITS haplotype diversity and frequency of occurrence of apothecia. Each square represents a species. Only species with more than 20 specimens were considered for this analysis. Correlation test $p<0.05 ; R^{2}=0.5554$. (C) Rarefaction curve showing the distribution of the number if ITS haplotypes as a function of the number of samples per section. Shaded areas represent the 95\% confidence intervals. (D) Frequencies of specimens with apothecia in sections Chloropeltigera and Peltidea.

Nostoc phylogroups associated with the three Peltigera sections of trimembered species (e.g., phylogroup V) are known to associate with Peltigera species from other sections, which also occur outside of the boreal biome (O'Brien et al., 2013; Magain et al., 2016). A previous study suggested that cyanobiont composition has evolved differently in bimembered and trimembered lichens (Lohtander et al., 2003). However, this seems unlikely as several phylogroups are shared between biand trimembered Peltigera species from different sections, as well as mycobionts from other genera within the order Peltigerales (Figure 2).

\section{Evolution of Specificity in Sections Chloropeltigera and Peltidea}

Two contrasting patterns of mycobiont specificity toward their Nostoc partners were observed in sections Chloropeltigera and Peltidea (Figure 4). With the same number of putative species in both sections, mycobionts from Chloropeltigera associate with nine different phylogroups of Nostoc, whereas mycobionts from Peltidea with only four. Moreover, no putative species in section Peltidea was found to associate with more than two Nostoc phylogroups, while in section Chloropeltigera, one putative species was associated with seven different Nostoc phylogroups (Figure 4). The occurrence of generalist trimembered Peltigera species in section Chloropeltigera does not support the hypothesis that trimembered lichen-forming fungi tend to be more specialized than bimembered species as suggested by Elvebakk et al. (2008) in the family Pannariaceae. Specificity of lichen-forming fungi and their photobionts seems to be clade dependent. For example, our study shows that some members from section Peltidea as well as their Nostoc partners (from Nostoc subclade 2) are highly specific toward each other, confirming, based on a broader geographic sampling, high reciprocal specificity between Nostoc phylogroup III and P. malacea (O’Brien et al., 2013; Miadlikowska et al., 2018). 
Previous studies suggest that geographic and ecological factors can drive the differences in the specificity of the association in both cyano- and chlorolichens (Fedrowitz et al., 2012; Muggia et al., 2014). Overall, cases of one-to-one specificity are very rare in lichens. Some exceptions to this trend include two Peltigera species from section Polydactylon ( $P$. neopolydactyla 5 and $P$. sp. 11 associated with phylogroups XIb and IX, respectively) reported by Magain et al. (2017a), and five species of gelatinous lichens in the Collemataceae (Otálora et al., 2010). Usually, mycobiont species are specialized on a few Nostoc lineages, and Nostoc phylogroups associate with a broader set of mycobiont species (Myllys et al., 2007; Magain et al., 2017a; but see Blaha et al., 2006). The uniqueness of the specificity pattern detected in $P$. malacea might indicate that reversion to a bimembered thallus (Miadlikowska and Lutzoni, 2004; Figure 4) evolved not only through the loss of the green alga Coccomyxa but also through replacement of the ancestral cyanobiont(s) by a Nostoc from phylogroup III (Figure 2). The overall observed association pattern might indicate that a transition to a symbiotic association with Nostoc subclade 2 could have driven the specialization of Peltigera species in section Peltidea (Figure 4).

The relatively small number of individuals sampled from some species in section Peltidea (Figure 4) make it difficult to establish whether they are specialist or non-specialist (Magain et al., 2017b). To get around this, we assessed the degree of specificity by comparing the distribution of the number of Nostoc phylogroups as a function of the number of samples at the section level. Our results support previous insights on cyanobiont specificity reported from selected lineages in section Peltidea (Paulsrud et al., 1998; O'Brien et al., 2013) and show that species in section Chloropeltigera are generalists, compared to species in section Peltidea, in their association with Nostoc phylogroups (Figure 5A).

Several mechanisms have been proposed to explain differences in specificity in lichens. Differences in rate of mycobiont diversification have been shown to affect specificity in Peltigera section Polydactylon (Magain et al., 2017a). However, no significant rate shifts were found among trimembered lineages (data not shown). Limited geographic distribution and photobiont availability may also be a factor (Dal Grande et al., 2014), but as outlined earlier, most mycobionts and cyanobionts are widespread across the boreal biome. Also, there seems to be a preference for different photobiont lineages at the section level, with Peltidea associating mainly with Nostoc from subclade 2, and Chloropeltigera only associating with Nostoc from subclade 3 (Figure 4). These preferential interactions found in trimembered sections are in agreement with an anti-nested pattern of association detected with ecological networks analyses to assess the structure of symbiotic interactions in section Polydactylon at a global scale (Chagnon et al., 2018). For comparison, bimembered lichen-forming fungi from the genus Protoparmelia, associated with green algae (Trebouxia spp.) have been shown to vary in their specificity depending on macroclimatic variables (Singh et al., 2017). Although the Peltigera species studied here generally do not occupy geographic regions with contrasting macroclimates, it is possible that microclimatic differences exist within the distributions of species from different sections, and that such differences might affect symbiont availability and the association patterns. However, a co-occurrence study of the genus Peltigera and their Nostoc partners along a longitudinal and latitudinal transect of nearly $1300 \mathrm{~km}$ each, in the boreal biome, revealed that bioclimatic factors at this spatial scale were more limiting for the ranges of Peltigera species than the availability of their Nostoc partners (Lu et al., 2018).

Modes of reproduction can drive variation in specificity because it translates directly into how photobionts are transmitted from one generation to the next (Otálora et al., 2010; Dal Grande et al., 2012; Hestmark et al., 2016). We looked for signatures of sexual and asexual reproduction by examining whether there was a correlation between the presence of sexual structures (apothecia) on lichen thalli of sections Peltidea and Chloropeltigera, and their ITS haplotype diversity. Although our molecular sampling was not designed to test directly the prevalence of different types of reproduction, we found a significant positive correlation between the frequency of occurrence of apothecia and ITS haplotype diversity of the mycobiont (Figure 5B). We used these two variables as a proxy to assess the possible role of reproductive modes in shaping the observed specificity patterns. We found that both the ITS haplotype diversity and the frequency of apothecia were higher in section Chloropeltigera than in section Peltidea (Figures 5C-D). We expect that asexually reproducing species (involving vertical transmission of photobionts) will display specialist patterns of association with their photobionts even if they do not have specialized vegetative propagules (such as soredia and isidia) containing the mycobiont and photobiont, but instead can disperse through thallus fragments, whereas sexually reproducing species (horizontal transmission of photobiont) are more likely to be generalists. The role of asexual reproduction in the specificity of association toward Nostoc has been shown for a species pair in Degelia (Otálora et al., 2013) as well as for Collema and Leptogium species with contrasting modes of reproduction (Otálora et al., 2010). Magain et al. (2017a) also observed a trend for higher level of specificity in predominantly asexual species of Peltigera in section Polydactylon. However, when this hypothesis was tested in bimembered lichen-forming fungi associated with green algae, their reproductive mode was not a good predictor of the level of specificity (Wornik and Grube, 2010). Our findings for trimembered lichens are in agreement with conclusions based on bimembered cyanolichens and lichens associated solely with green algae, because asexual reproduction seems to increase the specificity toward Nostoc but not toward Coccomyxa (Figure 4). It has been hypothesized that symbiotic interactions can trigger switches in reproductive mode (Buschbom and Mueller, 2006); however, the specific conditions promoting these selective sweeps remain unknown. These observations and predictions should be further addressed in studies specifically designed to determine the factors driving sexual vs. asexual reproduction in lichen-forming fungi, and the evolutionary and genetic mechanisms shaping specificity levels. 


\section{AUTHOR CONTRIBUTIONS}

FL, JM, NM, TG, and CP-D conceived the study. FL, JM, TG, and NM collected the samples. CP-D and NM obtained the molecular data. CP-D performed the phylogenetic and statistical analyses. CP-D, NM, FL, TG, SR, and JM wrote the manuscript.

\section{FUNDING}

This work was supported by the National Science Foundation awards DEB-1025930 and DEB-1556995 to JM and FL, as well as DEB-1046065 to FL.

\section{REFERENCES}

Blaha, J., Baloch, E., and Grube, M. (2006). High photobiont diversity associated with the euryoecious lichen-forming ascomycete Lecanora rupicola (Lecanoraceae, Ascomycota). Biol. J. Linn. Soc. 88, 283-293. doi: 10.1111/j. 1095-8312.2006.00640.x

Blanc, G., Agarkova, I., Grimwood, J., Kuo, A., Brueggeman, A., Dunigan, D. D., et al. (2012). The genome of the polar eukaryotic microalga Coccomyxa subellipsoidea reveals traits of cold adaptation. Genome Biol. 13:R39. doi: 10 . 1186/gb-2012-13-5-r39

Buschbom, J., and Mueller, G. M. (2006). Testing "species pair" hypotheses: evolutionary processes in the lichen-forming species complex Porpidia flavocoerulescens and Porpidia melinodes. Mol. Biol. Evol. 23, 574-586. doi: 10.1093/molbev/msj063

Chagnon, P. L., Magain, N., Miadlikowska, J., and Lutzoni, F. (2018). Strong specificity and network modularity at a very fine phylogenetic scale in the lichen genus Peltigera. Oecologia 187, 767-782. doi: 10.1007/s00442-0184159-6

Dal Grande, F., Beck, A., Cornejo, C., Singh, G., Cheenacharoen, S., Nelsen, M. P., et al. (2014). Molecular phylogeny and symbiotic selectivity of the green algal genus Dictyochloropsis sl (Trebouxiophyceae): a polyphyletic and widespread group forming photobiont-mediated guilds in the lichen family Lobariaceae. New Phytol. 202, 455-470. doi: 10.1111/nph.12678

Dal Grande, F., Rolshausen, G., Divakar, P. K., Crespo, A., Otte, J., Schleuningand, M., et al. (2018). Environment and host identity structure communities of green algal symbionts in lichens. New Phytol. 217, 277-289. doi: $10.1111 /$ nph. 14770

Dal Grande, F., Widmer, I., Wagner, H. H., and Scheidegger, C. (2012). Vertical and horizontal photobiont transmission within populations of a lichen symbiosis. Mol. Ecol. 21, 3159-3172. doi: 10.1111/j.1365-294X.2012.05 482.x

Darienko, T., Gustavs, L., Eggert, A., Wolf, W., and Pröschold, T. (2015). Evaluating the species boundaries of green microalgae (Coccomyxa, Trebouxiophyceae, Chlorophyta) using integrative taxonomy and DNA barcoding with further implications for the species identification in environmental samples. PLoS One 10:e0127838. doi: 10.1371/journal.pone. 0127838

Drummond, A. J., Ashton, B., Buxton, S., Cheung, M., Cooper, A., Duran, C., et al. (2011). Geneious v5.4. Available at: http://www.geneious.com/

Drummond, A. J., Rambau, A., and Suchard, M. (2013). BEAST 1.8.0. Available at: http://beast.bio.ed.ac.uk

Drummond, A. J., and Rambaut, A. (2007). BEAST: Bayesian evolutionary analysis by sampling trees. BMC Evol. Biol. 7:1. doi: 10.1186/1471-2148-7-214

Elvebakk, A., Papaefthimiou, D., Robertsen, E. H., and Liaimer, A. (2008). Phylogenetic patterns among Nostoc cyanobionts within bi-and tripartite lichens of the genus Pannaria. J. Phycol. 44, 1049-1059. doi: 10.1111/j.15298817.2008.00556.x

Etges, S., and Ott, S. (2001). Lichen mycobionts transplanted into the natural habitat. Symbiosis 30, 191-206.

\section{ACKNOWLEDGMENTS}

We thank Bernard Goffinet, James Lendemer, and Jaen S. Hur for kindly providing many lichen specimens used in this study. We also thank Eimy Rivas-Plata for generating some of the molecular data and Elena A. Ritschard for her assistance in the preparation of the figures.

\section{SUPPLEMENTARY MATERIAL}

The Supplementary Material for this article can be found online at: https://www.frontiersin.org/articles/10.3389/fmicb. 2018.02770/full\#supplementary-material

Fedrowitz, K., Kaasalainen, U., and Rikkinen, J. (2011). Genotype variability of Nostoc symbionts associated with three epiphytic Nephroma species in a boreal forest landscape. Bryologist 114, 220-230. doi: 10.1639/0007-2745-114.1.220

Fedrowitz, K., Kaasalainen, U., and Rikkinen, J. (2012). Geographic mosaic of symbiont selectivity in a genus of epiphytic cyanolichens. Ecol. Evol. 2, 2291-2303. doi: 10.1002/ece3.343

Fernández-Mendoza, F., Domaschke, S., García, M. A., Jordan, P., Martín, M. P., and Printzen, C. (2011). Population structure of mycobionts and photobionts of the widespread lichen Cetraria aculeata. Mol. Ecol. 20, 1208-1232. doi: 10. 1111/j.1365-294X.2010.04993.x

Feuerer, T. (2016). The index of checklists of lichens and lichenicolous fungi. Available at: http://www.lichens.uni-hamburg.de/lichens/portalpages/ portalpage_biodiversity_switch.htm

Feuerer, T., and Hawksworth, D. L. (2007). Biodiversity of lichens, including a world-wide analysis of checklist data based on Takhtajan's floristic regions. Bio. Cons. 16, 85-98. doi: 10.1007/s10531-006-9142-6

Glass, N. L., and Donaldson, G. C. (1995). Development of primer sets designed for use with the PCR to amplify conserved genes from filamentous ascomycetes. Appl. Environ. Microbiol. 61, 1323-1330.

Goffinet, B., Miadlikowska, J., and Goward, T. (2003). Phylogenetic inferences based on nrDNA sequences support five morphospecies within the Peltigera didactyla complex (lichenized Ascomycota). Bryologist 106, 349-364. doi: 10. $1639 / 01$

Goward, T., and Goffinet, B. (2000). Peltigera chionophila, a new lichen (Ascomycetes) from the Western Cordillera of North America. Bryologist 103, 493-498.

Hestmark, G., Lutzoni, F., and Miadlikowska, J. (2016). Photobiont associations in co-occurring umbilicate lichens with contrasting modes of reproduction in coastal Norway. Lichenologist 48, 545-557. doi: 10.1017/S0024282916000232

Hsieh, T. C., Ma, K. H., and Chao, A. (2013). iNEXT: iNterpolation and EXTrapolation for Species Diversity. R Package Version 1.

Holtan-Hartwig, J. (1993). The Lichen Genus 'Peltigera', Exclusive of the 'P. Canina' Group, in Norway. Oslo: University of Oslo.

Holtan-Hartwig, J. (2005). Peltigera latiloba, a new lichen species from Norway and USA (Alaska). Graphis Scripta 17:34.

Honegger, R. (2009). "Lichen-forming fungi and their photobionts," in Plant Relationships, ed. H. B. Deising (Heidelberg: Springer), 307-333. doi: 10.1007/ 978-3-540-87407-2_16

Kaasalainen, U., Fewer, D. P., Jokela, J., Wahlsten, M., Sivonen, K., and Rikkinen, J. (2012). Cyanobacteria produce a high variety of hepatotoxic peptides in lichen symbiosis. Proc. Natl. Acad. Sci. U.S.A. 109, 5886-5891. doi: 10.1073/pnas. 1200279109

Katoh, K., and Standley, D. M. (2013). MAFFT multiple sequence alignment software version 7: improvements in performance and usability. Mol. Biol. Evol. 30, 772-780. doi: 10.1093/molbev/mst010

Lanfear, R., Calcott, B., Ho, S. Y. W., and Guindon, S. (2012). PartitionFinder: combined selection of partitioning schemes and substitution models for phylogenetic analyses. Mol. Biol. Evol. 29, 1695-1701. doi: 10.1093/molbev/ mss020 
Leavitt, S. D., Moreau, C. S., and Lumbsch, H. T. (2015). “The dynamic discipline of species delimitation: progress toward effectively recognizing species boundaries in natural populations," in Recent Advances in Lichenology, eds D. K. Upreti, P. K. Divakar, V. Shukla, and R. Bajpai (New Delhi: Springer), 11-44. doi: 10.1007/978-81-322-2235-4_2

Leavitt, S. D., Nelsen, M. P., Lumbsch, H. T., Johnson, L. A., and St. Clair, L. L. (2013). Symbiont flexibility in subalpine rock shield lichen communities in the Southwestern USA. Bryologist 116, 149-161. doi: 10.1639/0007-2745-116. 2.149

Lohtander, K., Oksanen, I., and Rikkinen, J. (2003). Genetic diversity of green algal and cyanobacterial photobionts in Nephroma (Peltigerales). Lichenologist 35, 325-339. doi: 10.1016/S0024-2829(03)00051-3

Louthan, A. M., Doak, D. F., and Angert, A. L. (2015). Where and when do species interactions set range limits? Trends Ecol. Evol. 30, 780-792. doi: 10.1016/j.tree. 2015.09.011

Lu, J., Magain, N., Miadlikowska, J., Coyle, J. R., Truong, C., and Lutzoni, F. (2018). Bioclimatic factors at an intrabiome scale are more limiting than cyanobiont availability for the lichen-forming genus Peltigera. Am. J. Bot. 105, 1198-1211. doi: 10.1002/ajb2.1119

Lumbsch, H. T., and Leavitt, S. D. (2011). Goodbye morphology? A paradigm shift in the delimitation of species in lichenized fungi. Fungal Div. 50, 59-72. doi: 10.1007/s13225-011-0123-z

Lutzoni, F., Wagner, P., Reeb, V., and Zoller, S. (2000). Integrating ambiguously aligned regions of DNA sequences in phylogenetic analyses without violating positional homology. Syst. Biol. 49, 628-651. doi: 10.1080/106351500750049743

Maddison, D. R., and Maddison, W. P. (2005). MacClade v. 4.08. Sunderland, MA: Sinauer Associates.

Maddison, W. P., and Maddison, D. R. (2010). Mesquite: A Modular System for Evolutionary Analysis Version 2.75.

Magain, N., Miadlikowska, J., Goffinet, B., Sérusiaux, E., and Lutzoni, F. (2017a). Macroevolution of specificity in cyanolichens of the genus Peltigera section Polydactylon (Lecanoromycetes, Ascomycota). Syst. Biol. 66, 74-99. doi: 10. 1093/sysbio/syw065

Magain, N., Miadlikowska, J., Mueller, O., Gajdeczka, M., Truong, C., Salamov, A., et al. (2017b). Conserved genomic collinearity as a source of broadly applicable, fast evolving, markers to resolve species complexes: a case study using the lichen-forming genus Peltigera section Polydactylon. Mol. Phylogenet. Evol. 117, 10-29. doi: 10.1016/j.ympev.2017.08.013

Magain, N., and Sérusiaux, E. (2014). Do photobiont switch and cephalodia emancipation act as evolutionary drivers in the lichen symbiosis? A case study in the Pannariaceae (Peltigerales). PLoS One 9:e89876. doi: 10.1371/journal. pone.0089876

Magain, N., Sérusiaux, E., Zhurbenko, M. P., Lutzoni, F., and Miadlikowska, J. (2016). Disentangling the Peltigera polydactylon species complex by recognizing two new taxa, P. polydactylon subsp. udeghe and P. seneca. Herzogia 29, 514-528. doi: 10.13158/heia.29.2.2016.514

Malavasi, V., Škaloud, P., Rindi, F., Tempesta, S., Paoletti, M., and Pasqualetti, M. (2016). DNA-based taxonomy in ecologically versatile microalgae: a reevaluation of the species concept within the coccoid green algal genus Coccomyxa (Trebouxiophyceae, Chlorophyta). PLoS One 11:e0151137. doi: 10. 1371/journal.pone.0151137

Martínez, I., Burgaz, A. R., Vitikainen, O., and Escudero, A. (2003). Distribution patterns in the genus Peltigera Willd. Lichenologist 35, 301-323. doi: 10.1016/ S0024-2829(03)00041-0

Matheny, P. B., Liu, Y. J., Ammirati, J. F., and Hall, B. D. (2002). Using RPB1 sequences to improve phylogenetic inference among mushrooms (Inocybe, Agaricales). Am. J. Bot. 89, 688-698. doi: 10.3732/ajb.89.4.688

Miadlikowska, J., Magain, N., Pardo-De la Hoz, C. J., Niu, D., Goward, T., Serusiaux, E., et al. (2018). Species in section Peltidea (aphthosa group) of the genus Peltigera remain cryptic after molecular phylogenetic revision. Plant Fungal Syst. 63.

Miadlikowska, J., and Lutzoni, F. (2000). Phylogenetic revision of the Genus Peltigera (Lichen-Forming Ascomycota) Based on Morphological, Chemical, and Large Subunit Nuclear Ribosomal DNA Data. Int. J. Plant Sci. 161, 925-958. doi: $10.1086 / 317568$

Miadlikowska, J., Lutzoni, F., Goward, T., Zoller, S., and Posada, D. (2003). New approach to an old problem: Incorporating signal from gap-rich regions of ITS and rDNA large subunit into phylogenetic analyses to resolve the Peltigera canina species complex. Mycologia 95, 1181-1203. doi: 10.1080/15572536.2004. 11833027

Miadlikowska, J., and Lutzoni, F. (2004). Phylogenetic classification of peltigeralean fungi (Peltigerales, Ascomycota) based on ribosomal RNA small and large subunits. Am. J. Bot. 91, 449-464. doi: 10.3732/ajb.91.3.449

Miadlikowska, J., Richardson, D., Magain, N., Ball, B., Anderson, F., Cameron, R., et al. (2014). Phylogenetic placement, species delimitation, and cyanobiont identity of endangered aquatic Peltigera species (lichen-forming Ascomycota, Lecanoromycetes). Am. J. Bot. 101, 1141-1156. doi: 10.3732/ajb.140 0267

Miller, M. A., Pfeiffer, W., and Schwartz, T. (2010). "Creating the CIPRES Science Gateway for inference of large phylogenetic trees," in Proceedings of the 2010 Gateway Computing Environments Workshop (GCE), New Orleans, LA. doi: 10.1109/GCE.2010.5676129

Moya, P., Molins, A., Martínez-Alberola, F., Muggia, L., and Barreno, E. (2017). Unexpected associated microalgal diversity in the lichen Ramalina farinacea is uncovered by pyrosequencing analyses. PLoS One 12:e0175091. doi: 10.1371/ journal.pone.0175091

Muggia, L., Baloch, E., Stabentheiner, E., Grube, M., and Wedin, M. (2011). Photobiont association and genetic diversity of the optionally lichenized fungus Schizoxylon albescens. FEMS Microbiol. Ecol. 75, 255-272. doi: 10.1111/j.15746941.2010.01002.x

Muggia, L., Pérez-Ortega, S., Kopun, T., Zellnig, G., and Grube, M. (2014). Photobiont selectivity leads to ecological tolerance and evolutionary divergence in a polymorphic complex of lichenized fungi. Ann. Bot. 114, 463-475. doi: 10.1093/aob/mcu146

Muggia, L., Vancurova, L., Škaloud, P., Peksa, O., Wedin, M., and Grube, M. (2013). The symbiotic playground of lichen thalli-a highly flexible photobiont association in rock-inhabiting lichens. FEMS Microbiol. Ecol. 85, 313-323. doi: 10.1111/1574-6941.12120

Muggia, L., Zellnig, G., Rabensteiner, J., and Grube, M. (2010). Morphological and phylogenetic study of algal partners associated with the lichen-forming fungus Tephromela atra from the Mediterranean region. Symbiosis 51, 149-160. doi: 10.1007/s13199-010-0060-8

Myllys, L., Stenroos, S., Thell, A., and Kuusinen, M. (2007). High cyanobiont selectivity of epiphytic lichens in old growth boreal forest of Finland. New Phytol. 173, 621-629. doi: 10.1111/j.1469-8137.2006.01944.x

Nei, M., and Tajima, F. (1981). DNA polymorphism detectable by restriction endonucleases. Genetics 97, 145-163.

O’Brien, H. E., Miadlikowska, J., and Lutzoni, F. (2005). Assessing host specialization in symbiotic cyanobacteria associated with four closely related species of the lichen fungus Peltigera. Eur. J. Phycol. 40, 363-378. doi: 10.1080/ 09670260500342647

O'Brien, H. E., Miadlikowska, J., and Lutzoni, F. (2009). Assessing reproductive isolation in highly diverse communities of the lichen-forming fungal genus Peltigera. Evolution 63, 2076-2086. doi: 10.1111/j.1558-5646.2009.00685.x

O’Brien, H. E., Miadlikowska, J., and Lutzoni, F. (2013). Assessing population structure and host specialization in lichenized cyanobacteria. New Phytol. 198, 557-566. doi: 10.1111/nph.12165

Oliver, J. C., Miadlikowska, J., Arnold, A. E., Maddison, D. R., and Lutzoni, F. (2013). Hypha: A Mesquite Package for Support Value Integration. Version 1.0.

Otálora, M. A., Aragón, G., Martínez, I., and Wedin, M. (2013). Cardinal characters on a slippery slope-a re-evaluation of phylogeny, character evolution, and evolutionary rates in the jelly lichens (Collemataceae s. str). Mol. Phylogenet. Evol. 68, 185-198. doi: 10.1016/j.ympev.2013.04.004

Otálora, M. A. G., Martínez, I., O’Brien, H., Molina, M. C., Aragón, G., and Lutzoni, F. (2010). Multiple origins of high reciprocal symbiotic specificity at an intercontinental spatial scale among gelatinous lichens (Collemataceae). Mol. Phylogenet. Evol. 56, 1089-1095. doi: 10.1016/j.ympev.2010.05.013

Pardo-De la Hoz, C. J., Magain, N., Lutzoni, F., Goward, T., Restrepo, S., and Miadlikowska, J. (2018). Contrasting Symbiotic Patterns in Two Closely Related Lineages of Trimembered Lichens of the Genus Peltigera. TreeBASE. Version 1.

Paulsrud, P., Rikkinen, J., and Lindblad, P. (1998). Cyanobiont specificity in some Nostoc-containing lichens and in a Peltigera aphthosa photosymbiodeme. New Phytol. 139, 517-524. doi: 10.1046/j.1469-8137.1998. 00220.x

Perez-Ortega, S., Ortiz-Álvarez, R., Green, T. G. A., and de los Rios, A. (2012). Lichen myco-and photobiont diversity and their relationships at the edge of 
life (McMurdo Dry Valleys, Antarctica). FEMS Microbiol. Ecol. 82, 429-448. doi: 10.1111/j.1574-6941.2012.01422.x

Rambaut, A., and Drummond, A. (2013). Tracer 1.6. Available at: https://github. com/beast-dev/tracer/releases

Rambaut, A., and Drummond, A. J. (2015). LogCombiner v1. 8.2. Available at: http://beast.bio.ed.ac.uk

Rannala, B., and Yang, Z. (2003). Bayes estimation of species divergence times and ancestral population sizes using DNA sequences from multiple loci. Genetics 164, 1645-1656.

Reid, N. M., and Carstens, B. C. (2012). Phylogenetic estimation error can decrease the accuracy of species delimitation: a Bayesian implementation of the general mixed Yule-coalescent model. BMC Evol. Biol. 12:196. doi: 10.1186/1471-214812-196

Rikkinen, J. (2013). Molecular studies on cyanobacterial diversity in lichen symbioses. MycoKeys 6, 3-32. doi: 10.3897/mycokeys.6.3869

Rudi, K., Skulberg, O. M., and Jakobsen, K. S. (1998). Evolution of cyanobacteria by exchange of genetic material among phyletically related strains. J. Bacteriol. 180, 3453-3461.

Ruprecht, U., Brunauer, G., and Türk, R. (2014). High photobiont diversity in the common European soil crust lichen Psora decipiens. Biodiv. Conserv. 23, 1771-1785. doi: 10.1007/s10531-014-0662-1

Sato, H., Tanabe, A. S., and Toju, H. (2017). Host shifts enhance diversification of ectomycorrhizal fungi: diversification rate analysis of the ectomycorrhizal fungal genera Strobilomyces and Afroboletus with an 80-gene phylogeny. New Phytol. 214, 443-454. doi: 10.1111/nph.14368

Singh, G., Dal Grande, F., Divakar, P. K., Otte, J., Crespo, A., and Schmitt, I. (2017). Fungal-algal association patterns in lichen symbiosis linked to macroclimate. New Phytol. 214, 317-329. doi: 10.1111/nph.1 4366

Stamatakis, A. (2014). RAxML Version 8: a tool for phylogenetic analysis and post-analysis of large phylogenies. Bioinformatics 30, 1312-1313. doi: 10.1093/ bioinformatics/btu033

Stamatakis, A., Hoover, P., and Rougemont, J. (2008). A rapid bootstrap algorithm for the RAxML web servers. Syst. Biol. 57, 758-771. doi: 10.1080/ 10635150802429642

Stiller, J. W., and Hall, B. D. (1997). The origin of red algae: implications for plastid evolution. Proc. Natl. Acad. Sci. U.S.A. 94, 4520-4525. doi: 10.1073/pnas.94.9. 4520

Thompson, J. N. (2005). The Geographic Mosaic of Coevolution. Chicago, IL: University of Chicago Press.

Thüs, H., Muggia, L., Pérez-Ortega, S., Favero-Longo, S. E., Joneson, S., O’Brien, H., et al. (2011). Revisiting photobiont diversity in the lichen family Verrucariaceae (Ascomycota). Eur. J. Phycol. 46, 399-415. doi: 10.1080/09670262.2011.629788

Vitikainen, O. (1994). Taxonomic Revision of Peltigera (Lichenized Ascomycotina) in Europe. Helsinki: Finnish Zoological and Botanical Publishing Board.
Weir, B. S., Johnston, P. R., and Damm, U. (2012). The Colletotrichum gloeosporioides species complex. Stud. Mycol. 73, 115-180. doi: 10.3114/ sim0011

White, T. J., Bruns, T., Lee, S., Taylor, J. W., Helfand, D. H., Sninsky, J. J., et al. (1990). "Amplification and direct sequencing of fungal ribosomal RNA genes for phylogenetics," in PCR Protocols: A Guide to Methods and Applications, ed. M. A. Innis (New York, NY: Academic Press), 315-322. doi: 10.1016/B978-012-372180-8.50042-1

Wirtz, N., Lumbsch, H. T., Green, T. G., Türk, R., Pintado, A., Sancho, L. et al. (2003). Lichen fungi have low cyanobiont selectivity in maritime Antarctica. New Phytol. 160, 177-183. doi: 10.1046/j.1469-8137.2003. 00859.x

Wornik, S., and Grube, M. (2010). Joint dispersal does not imply maintenance of partnerships in lichen symbioses. Microb. Ecol. 59, 150-157. doi: 10.1007/ s00248-009-9584-y

Yahr, R., Florence, A., Škaloud, P., and Voytsekhovich, A. (2015). Molecular and morphological diversity in photobionts associated with Micarea s. str. (Lecanorales, Ascomycota). Lichenologist 47, 403-414. doi: 10.1017/ S0024282915000341

Yang, Z., and Rannala, B. (2010). Bayesian species delimitation using multilocus sequence data. Proc. Natl. Acad. Sci. U.S.A. 107, 9264-9269. doi: 10.1073/pnas. 0913022107

Zhang, J., Kapli, P., Pavlidis, P., and Stamatakis, A. (2013). A general species delimitation method with applications to phylogenetic placements. Bioinformatics 29, 2869-2876. doi: 10.1093/bioinformatics/ btt499

Zolan, M. E., and Pukkila, P. J. (1986). Inheritance of DNA methylation in Coprinus cinereus. Mol. Cell. Biol. 6, 195-200. doi: 10.1128/MCB.6. 1.195

Zoller, S., and Lutzoni, F. (2003). Slow algae, fast fungi: exceptionally high nucleotide substitution rate differences between lichenized fungi Omphalina and their symbiotic green algae Coccomyxa. Mol. Phylogenet. Evol. 29, 629-640. doi: 10.1016/S1055-7903(03)00215-

Conflict of Interest Statement: The authors declare that the research was conducted in the absence of any commercial or financial relationships that could be construed as a potential conflict of interest.

Copyright (c) 2018 Pardo-De la Hoz, Magain, Lutzoni, Goward, Restrepo and Miadlikowska. This is an open-access article distributed under the terms of the Creative Commons Attribution License (CC BY). The use, distribution or reproduction in other forums is permitted, provided the original author(s) and the copyright owner(s) are credited and that the original publication in this journal is cited, in accordance with accepted academic practice. No use, distribution or reproduction is permitted which does not comply with these terms. 